\title{
O EMPREENDEDORISMO SUSTENTÁVEL E O PROCESSO EMPREENDEDOR: EM BUSCA DE OPORTUNIDADES DE NOVOS NEGÓCIOS COMO SOLUÇÃO PARA PROBLEMAS SOCIAIS E AMBIENTAIS
}

\author{
SUSTAINABLE ENTREPRENEURSHIP AND THE ENTREPRENEURIAL \\ PROCESS: THE SEARCH FOR NEW BUSINESS OPPORTUNITIES AS A \\ SOLUTION FOR SOCIAL AND ENVIRONMENTAL ISSUES
}

\begin{abstract}
Anna Karina Boszczowski
Universidade Federal do Paraná UFPR Mestre em Administração annabosz@gmail.com

Rivanda Meira Teixeira

Doutora em Administração pela Cranfield University - Inglaterra e Professora do departamento em Administração e dos Mestrados em Administração e de Economia (NUPEC) da Universidade Federal de Sergipe. rivandateixeira@terra.com.br
\end{abstract}

Submissão: $20 / 04 / 2011$

Aprovação: 13/08/2012

\begin{abstract}
Resumo
Enquanto o empreendedorismo tem seu foco na criação de valor, o empreendedorismo sustentável amplia esse objetivo e engloba também o desenvolvimento sustentável e seus benefícios sociais e ambientais. O conceito do empreendedorismo sustentável envolve, portanto, identificação, criação e exploração de novos negócios que encontrem, no desenvolvimento econômico, a solução de um problema ambiental e social. Assim, de forma a entender o processo empreendedor como forma de estímulo do desenvolvimento econômico e solução de problemas ambientais e sociais, este ensaio teórico analisa as fontes e o processo de descoberta de oportunidades de negócios sustentáveis. Especificamente, discute a evolução do conceito de empreendedorismo sustentável, como as soluções para problemas ambientais e sociais podem se constituir em oportunidades de negócios sustentáveis e que fatores influenciam a identificação dessas oportunidades pelos empreendedores na criação de novos empreendimentos.
\end{abstract}


Abstract:

While entrepreneurship focus on the creation of economic value, sustainable entrepreneurship expands this goal and includes sustainable development and its social and environmental benefits. So the concept involves the discovery, creation and exploitation of new businesses that enable founders to obtains profits while solves environmental and social issues. To understand the entrepreneurial process as a mean to achieve sustainable development, this essay studies the opportunities for sustainable business sources and their discovery process. Initially presents how the concept and the study of opportunities for sustainable business sources evolved. Following examines the process of opportunities discovery and how it provides solutions to environmentally relevant market failures. In conclusion, these opportunities are recognized when the entrepreneur, cognitively relates, their knowledge and previous experience on a social or environmental cause to the means to satisfy it.

Keywords: sustainable entrepreneurship; opportunity identification; new business 


\section{INTRODUÇÃO}

O empreendedorismo é considerado por diversos autores como elemento fundamental no processo de desenvolvimento econômico (SHANE, 2000; VENKATARAMAN, 1997). Contudo seu papel na sociedade vai além da esfera econômica como fonte de geração de empregos, bem-estar e transformação (BHIDÉ, 2000) e engloba também a melhoria da qualidade ambiental e o desenvolvimento social (DELGADO et. al., 2008).

Nesse contexto, os empreendedores são estudados como agentes de mudança econômica e social, que podem ser motivados por outros fatores além da obtenção de lucros (DEES, 1998) e na criação de novos bens e serviços para a sociedade (SHANE; VENKATARAMAN, 2000). As motivações de cunho social são vastamente exploradas pela literatura (ELKINGTON; HARTIGAN, 2008; CHELL, 2007; MAIR; MARTI, 2006; WEEWARDENA, 2006), assim como sua preocupação com os problemas ambientais (SCHAPER, 2002; DIXON; CLIFFORD, 2007; SEELOS; MAIR, 2005; SCHALTEGGER, 2002). É a convergência desses campos de estudo que possibilita a aplicação do conceito de sustentabilidade $^{1}$ ao empreendedorismo (PARRISH, 2008), que originou a expressão empreendedorismo sustentável (DEAN; McMULLEN, 2007; COHEN; WINN, 2007) ou empreendedorismo orientado para o desenvolvimento sustentável ${ }^{2}$ (AHMED; McQUAID, 2005). Enquanto o empreendedorismo tem seu foco na criação de valor econômico (SHANE, 2000), o empreendedorismo sustentável amplia esse objetivo e abrange também o desenvolvimento sustentável e seus benefícios sociais e ambientais (JACOBS, 1995). O conceito do empreendedorismo sustentável envolve, portanto, a identificação, criação e exploração de novos negócios que encontrem, no desenvolvimento econômico, a solução de um problema ambiental e social.

Essa visão que relaciona o empreendedorismo ao desenvolvimento sustentável (DELGADO et. al., 2008) e postula seu papel na solução de problemas sociais e ambientais, vem emergindo como novo campo de pesquisa (DEAN; McMULLEN, 2007). Esse campo tem base também na literatura econômica que estuda a teoria de mercado e suas falhas. De

\footnotetext{
1 "O conceito de sustentabilidade emerge da construção de uma economia em que os recursos ambientais e as necessidades da sociedade como um todo estejam em equilíbrio, sem, no entanto, comprometerem as futuras gerações" (WORLD COMISSION ON ENVIROMENT AND DEVELOPMENT, 1987).

2 "O desenvolvimento sustentável é tido como aquele que satisfaz as necessidades presentes, sem comprometer a capacidade das gerações futuras de suprir suas próprias necessidades" (COMISSÃO MUNDIAL SOBRE MEIO AMBIENTE E DESENVOLVIMENTO, 1991).
} 
acordo com a teoria econômica, são as falhas de mercado ${ }^{3}$ inerentes ao livre mercado, que promovem as externalidades e ineficiências que se refletem nos problemas ambientais e sociais (COHEN; WINN, 2007, CROPPER; OATES, 1992).

A literatura de empreendedorismo postula que as imperfeições do mercado implicam oportunidades para ação empreendedora e ganhos econômicos. Dean e McMullen (2007) defendem o potencial do empreendedorismo na solução dessas falhas; Anderson e Leal (2001), especificamente, verificaram como solucionar os problemas ambientais; e Phillis e Denend (2005), os sociais. Nessa mesma lógica, as falhas de mercado também são apontadas como uma fonte de oportunidades para novos de negócios (COHEN, 2007), o que sugere que a busca por soluções para a crise social e ambiental proporciona ao empreendedor a identificação dessas oportunidades. Tradicionalmente se estudam os fatores e motivações que possibilitam ao empreendedor descobrir oportunidades para criação de valor econômico (KIRZNER, 1973; SHANE, 2000). No estudo da esfera social se consideram as motivações individuais para eleger uma causa social e para mercados sem fins lucrativos (ELKINGTON; HARTIGAN, 2008; CHELL, 2007; MAIR; MARTI, 2006; ALVAREZ; BARNEY, 2007; WEEWARDENA, 2006), enquanto as ambientais buscam explicar os fatores que motivam inovações de produtos e processos em soluções ambientais (SCHAPER, 2002; DIXON; CLIFFORD, 2007; SEELOS; MAIR, 2005; SCHALTEGGER, 2002). Cohen, Smith e Mitchell (2006) sugerem que, no empreendedorismo sustentável, a criação de valor do negócio será distinta de acordo com qual esfera de valor os motivos do empreendedor estarão relacionados, sendo que empreendedores sustentáveis seriam aqueles motivados pelas três esferas.

Identificar e selecionar a oportunidade certa para um novo negócio está entre as mais importantes habilidades de um empreendedor de sucesso (STEVENSON et al., 1985 apud ARDICHVILIA; CARDOZO; RAY, 2003). O processo de identificação de oportunidades é considerado também por Gartner (1995) e Bygrave (1997) como elemento principal do processo de criação de novos empreendimentos. Desse modo, considerando que a criação de negócios de sucesso é precedida de um sucesso no processo de reconhecimento da oportunidade e objetivando entender o processo empreendedor para estimular o desenvolvimento econômico e a solução de problemas ambientais e sociais, este artigo analisa as oportunidades de negócios sustentáveis. Especificamente, procura-se discutir a evolução do

\footnotetext{
${ }^{3}$ Segundo Zerbe e McCurdy (2000, p. 11, apud DEAN; MCMULLEN, 2007 p. 54), uma falha de mercado significa que o mercado falhou ao implementar todos os ganhos que poderiam ser obtidos a partir do livre comércio.
} 

conceito de empreendedorismo sustentável; como as soluções para problemas ambientais e sociais podem se constituir oportunidades de negócios sustentáveis; e que fatores influenciam na identificação dessas oportunidades pelos empreendedores na criação de novos empreendimentos.

O presente artigo é um ensaio teórico, uma análise lógica e reflexiva da literatura. Segundo Severino (2000, p. 152), um ensaio teórico é um estudo bem desenvolvido, formal, discursivo e concludente, consistindo numa exposição lógica e reflexiva e numa argumentação rigorosa, com alto nível de interpretação e julgamento. Com relação aos aspectos metodológicos, utilizou-se a pesquisa exploratória com a obtenção de dados secundários a partir da análise e comparação de livros e artigos disponíveis, tanto no formato impresso quanto na forma eletrônica. Para o levantamento, adotou-se o método de leitura científica proposto por Cervo e Bervian (2002), compreendendo a visão sincrética com a leitura de reconhecimento e seletiva, a visão analítica com a leitura crítico-reflexiva e, por fim, a visão sintética com a leitura interpretativa.

Como aproximação ao tema, foi realizada a revisão, a análise e a associação entre diferentes vertentes da literatura sobre o processo empreendedor à luz da teoria econômica. Essa estratégia promoveu um estudo comparativo entre os autores pesquisados, no qual se buscou encontrar semelhanças e particularidades com o objetivo formular hipóteses e não necessariamente alcançar um discurso conclusivo sobre as questões pesquisadas. 


\section{EMPREENDEDORISMO SUSTENTÁVEL}

O empreendedorismo sustentável é um tema de pesquisa novo e interdisciplinar que busca aproximar o campo de conhecimento do empreendedorismo ao da sustentabilidade. Ele emerge a partir de um grande número de pesquisas sobre negócios, meio ambiente e responsabilidade social, publicadas, principalmente, como uma resposta à necessidade de mudanças das empresas com relação a suas práticas sociais e ambientais.

Assim, a aproximação do empreendedorismo ao desenvolvimento sustentável passa pelo estudo das organizações como elemento aglutinador. Por um lado, porque as organizações apresentam-se como uma ferramenta indispensável ao empreendedor para criação de valor (GARTNER, 1985; KATZ; GARTNER, 1988) e, por outro, porque constituem parte essencial da sociedade (MORGAN, 1996). No entanto, tradicionalmente, o estudo das organizações foi desenvolvido dissociado do campo relacionado com a biosfera e a comunidade (GLADWIN; KENNELY; KRAUSE, 1995), assim, se faz necessária uma mudança no campo de estudo da administração e dos negócios, de forma a inserir uma visão mais holística, tanto nos domínios econômicos quanto nas questões sociais e ambientais das organizações. É essa visão integrada que proporciona o entendimento do conceito de empreendedorismo sustentável.

Enquanto o foco de pesquisa do empreendedorismo recai sobre o indivíduo empreendedor, o processo de criação de novas organizações e seus impactos no sistema econômico (SHANE; VENKATARAMAN, 2000; GIBB, 1996; SHANE, 1996), o desenvolvimento sustentável apresenta como foco o desenvolvimento das sociedades e seus ecossistemas (LUMLEY; ARMSTRONG, 2004). De forma integrada, o empreendedorismo sustentável apresenta, como foco de estudo, o alcance da sociedade a benefícios sociais e ambientais (AHMED; McQUAID, 2005) na criação de empresas direcionadas pelo propósito de contribuir para o desenvolvimento ecológico e social do sistema em que vivem (PARRISH, 2008).

Ainda que os campos de pesquisa sobre empreendedorismo, organizações e desenvolvimento sustentável apresentem, individualmente, uma extensa publicação, o estudo do empreendedorismo sustentável, ou mais especificamente direcionado à sustentabilidade, ainda é muito pouco explorado. Com relação ao empreendedorismo, em uma revisão de artigos empíricos, Cohen e Winn (2007) encontraram que a integração da área ambiental com a econômica e social é praticamente negligenciada. Os campos mais estudados são suas áreas 

social e ambiental. Esses temas estão relacionados e são complementares do empreendedorismo sustentável (PARRISH, 2008), de modo que sua compreensão auxilia o entendimento do conceito.

O empreendedorismo social é uma área de pesquisa que foi consolidada no final da década de 90 (DEES, 1998; BOSCHEE, 1995). Mair e Marti (2006) apresentaram uma revisão das definições de empreendedorismo social em que agruparam a literatura em três grandes linhas. A primeira, e mais recorrente, se refere ao empreendedorismo social como iniciativas sem fins lucrativos em busca de estratégias ou princípios de gestão de forma a criar valor social (DEES, 1998; AUSTIN; STEVENSON; WEI-SKILLER, 2003; BOSCHEE, 1998). Um segundo grupo entende a prática de ações comerciais e de negócios de forma socialmente responsável e seu engajamento em parcerias setoriais (SAGAWA; SEGAL, 2000; WADDOCK, 1988). Por fim, um terceiro grupo entende o empreendedorismo social como uma forma de mitigar problemas sociais e catalisar a transformação da sociedade (PERRINI; VURRO, 2006 apud PARRISH, 2008; ALVORD; BROWN; LETTS, 2004). Zahra et al. (2008, p. 118) listaram uma revisão de mais de vinte definições e apresentaram como conceito de empreendedorismo social aquele que inclui todas as atividades e processos desenvolvidos para descobrir, definir e explorar oportunidades com o propósito de gerar riqueza social na criação de novos negócios ou no gerenciamento dos existentes de forma inovadora.

O empreendedorismo ambiental também se desenvolveu fortemente na década de 90, impulsionado pela crescente demanda da sociedade por qualidade ambiental e das empresas por apresentarem soluções para problemas ambientais. Termos como "Ecopreneuship" (DIXON; CLIFFORD, 2007), "Ecopreneur" (ISAAK, 2002; WALLEY; TAYLOR, 2002) e "Green Entrepreneuship" (WALLEY; TAYLOR, 2002) foram criados para conceituar empreendedores com motivações ambientais. De forma geral, o empreendedorismo ambiental está associado a oportunidades de novos negócios criadas pelas inovações ecológicas (SCHALTEGGER, 2002). Segundo SCHAPER (2002), três temas dominam essa literatura: o desenvolvimento de tipologias para distinguir as diversas variedades de empreendedorismo com fins ambientais (ISAAK, 2002; FREIMANN; MARXEN; SCHICK 2002), a identificação de fatores que promovem seu desenvolvimento (WALLEY; TAYLOR, 2002; PASTAKIA, 2002) e aqueles que exploram o quanto empreendedores podem catalisar grandes transformações na economia (BRYANT; BRYANT, 1998; ANDERSON, 1998).

Por fim, o empreendedorismo sustentável teve um aumento expressivo de publicações apenas nos últimos cinco anos, quando diversos estudos foram realizados. Trabalhos como o 
de Gerlach (2006, p. 75), que conceitua os empreendedores sustentáveis como aqueles que iniciam e implementam inovações sustentáveis e que perseguem objetivos sociais ou ecológicos além de buscarem o sucesso financeiro, e o de Hockerts (2003, apud GERLACH, 2006, p. 75), que aplica o termo à identificação de inovações sustentáveis e sua implementação tanto através de um novo negócio ou uma reorientação radical de um modelo de negócio pré-existente de forma a atingir benefícios sociais, ambientais e econômicos", estão entre os primeiros que apresentaram o tema.

Alguns autores também exploraram a contribuição das formas convencionais de empreendedorismo para o desenvolvimento sustentável por meio da geração de empregos, facilitando a introdução de inovações ecológicas e a introdução, no mercado, de novos bens e serviços (AHMED; McQUAID, 2005). Outros direcionaram seus estudos sob o nome de empreendedorismo sustentável, mas limitaram seu foco exclusivamente às questões ambientais (DEAN; McMULLEN, 2007). Parrish (2008) apresenta um conceito mais integrado ao de desenvolvimento sustentável, considerando este como o tipo de empreendedorismo que explicitamente introduz dimensões tanto sociais quanto ambientais ao desenvolvimento de uma empresa com o objetivo de crescimento econômico assim como de continuidade do homem no planeta.

O mesmo princípio está apresentado nos trabalhos de Tilley e Young (2009, p. 86) e Tilley e Parrish (2006 apud PARRISH 2008, p. 29). Ambos os trabalhos consideram a existência dos três focos de atuação para empreendedores: o social, o ambiental e o econômico. A inter-relação dos três introduz uma quarta dimensão denominada de sustentável. O empreendedor sustentável seria o indivíduo que promove a integração desses três componentes de forma holística. O empreendedorismo sustentável é considerado um processo que cria empresas, as quais, em sua interação com os humanos e os sistemas ecológicos, podem vir a contribuir para sua recuperação.

Para Cohen e Winn (2007), o conceito de empreendedorismo sustentável é complementar à definição de empreendedorismo apresentada por Venkataraman (1997, p. 120) como o campo de estudo que busca entender como oportunidades de desenvolver futuros bens e serviços são descobertas, criadas e exploradas, por quem e com quais consequências. Para Cohen e Winn (2007, p. 35), a definição de empreendedorismo sustentável é um campo de estudo que busca entender como oportunidades de desenvolver futuros bens e serviços são descobertas, criadas e exploradas, por quem e com quais consequências econômicas, sociais, psicológicas e ambientais. Por admitirem que os benefícios sociais decorrem de iniciativas 

ambientais (ex. a redução da poluição de rios aumenta a qualidade e a saúde da população ao seu entorno), de iniciativas econômicas e do impacto positivo do empreendedorismo no bemestar global de uma comunidade, os autores consideram que cada um dos três aspectos da sustentabilidade está incorporado ao conceito.

Dean e Mcmullen (2007, p. 58) também utilizam a definição de Venkataraman (1997, p. 120) para apresentar o conceito, porém não exploram as consequências e sim a fonte da oportunidade a ser explorada pelo empreendedor. Dessa forma, definem-no como o processo de descoberta, avaliação e exploração econômica de oportunidades que se apresentam a partir de falhas de mercado oriundas da sustentabilidade. Cohen, Smith e Mitchell (2006) propõem uma definição do conceito em função das motivações do empreendedor, vendo o empreendedorismo sustentável como aquele em que ocorre a busca por lucros a partir da criação de valor econômico, social e ambiental. Dixon e Clifford (2007) já haviam utilizado esse mesmo conceito em um estudo de caso sobre empreendedorismo ambiental. Ainda que não se mencionasse o termo, o caso apresenta uma pequena empresa na qual se cria valor econômico como meio para atingir seu fim social e ambiental.

Schlange (2007) posiciona o conceito relacionando os empreendedores sustentáveis com seus stakeholders. Dessa forma, eles seriam aqueles que visualizam seus empreendimentos como parte de um contexto social amplo e contribuiriam para uma melhoria geral das condições de vida da sociedade. Esses empreendedores seriam direcionados pelo princípio de atendimento às necessidades presentes dos stakeholders, sem comprometer suas necessidades futuras.

Parrish (2008) considera que, quando o objetivo de geração de valor econômico de uma empresa é diminuído, o potencial de contribuição para o desenvolvimento sustentável aumenta. Em face desse argumento, o autor apresenta a evolução do conceito a partir dos autores discutidos nesta seção. O esquema representativo, adaptado pela autora, pode ser visualizado na Figura 1. 
Figura 1 - Evolução e expansão do conceito de empreendedorismo sustentável

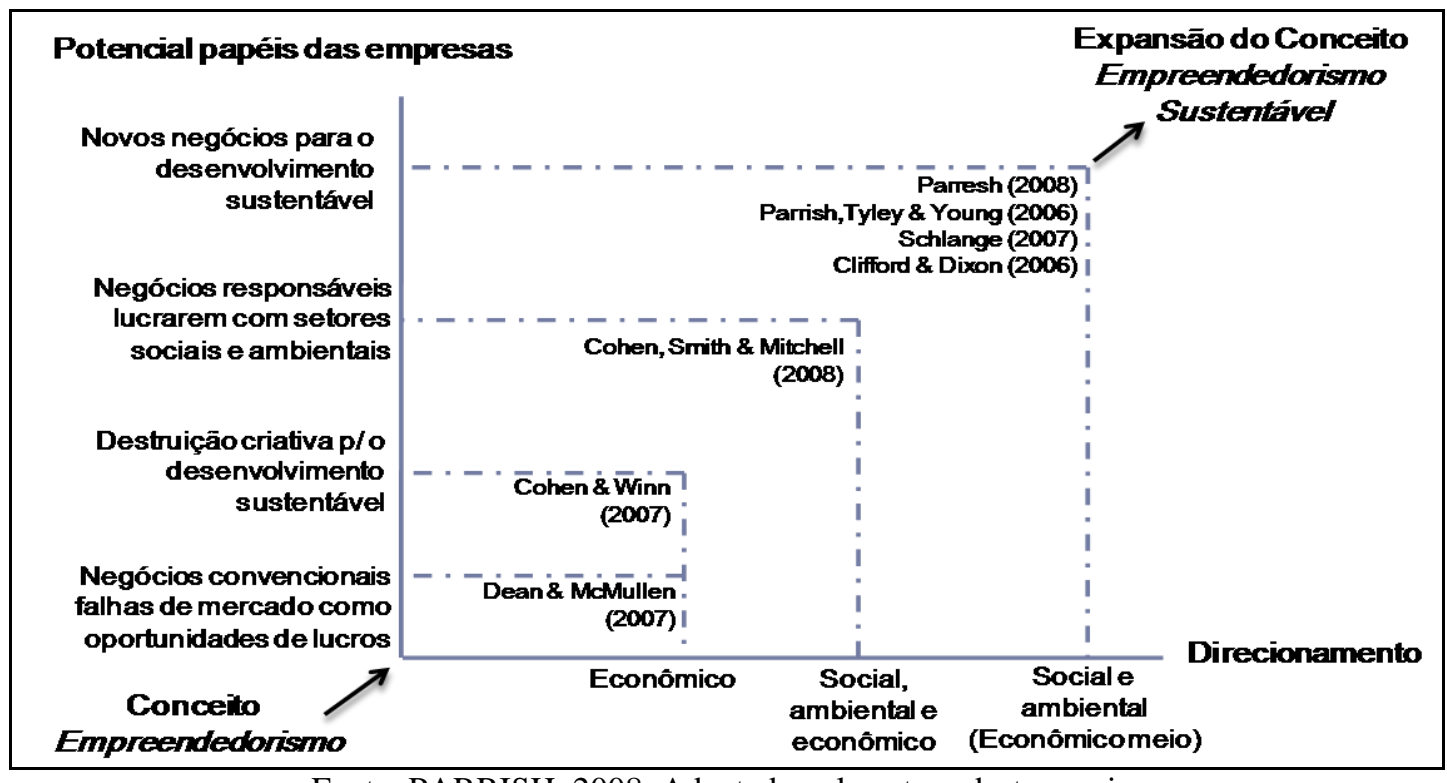

Fonte: PARRISH, 2008. Adaptado pela autora deste ensaio. 


\section{OPORTUNIDADES DE NEGÓCIOS SUSTENTÁVEIS}

Shane e Venkataraman (2000, p. 218) definem o campo de pesquisa do empreendedorismo como o estudo de como, por quem e com quais efeitos as oportunidades para criar futuros bens e serviços são descobertas, avaliadas e exploradas. Grande parte da pesquisa desenvolvida no campo está focada em descoberta, exploração e consequências dessas oportunidades sem necessariamente explorar a natureza e a fonte (MCMULLEN; SHEPHERD, 2006) ${ }^{4}$. Assim, de forma a melhor apresentar o tema "oportunidades de negócios sustentáveis", este trabalho se inicia com uma discussão da natureza e da fonte de entrepreneurial opportunities, seguida do processo de descoberta, avaliação e exploração, relacionando o tema ao desenvolvimento sustentável e aos conceitos apresentados na seção anterior.

Uma entrepreneurial opportunity pode ser descrita como uma oportunidade de se engajar em uma ação empreendedora, a qual, sendo uma ação humana e utilizando um raciocínio racional, é motivada, preferencialmente pela criação de valor econômico (HOMANS, 1964 apud COMPANYS; McMULLEN, 2007 p. 303). A oportunidade é a situação em que a ação empreendedora poderá atingir seu objetivo de gerar valor econômico com a criação de novos bens e serviços (COMPANYS; McMULLEN, 2007). Esse argumento é coerente com o apresentado por Casson (1982 apud SHANE; VENKATARAMAN 2000, p. 220), ao argumentarem que, no campo do empreendedorismo, oportunidades são aquelas situações nas quais novos bens, serviços, matérias-primas e métodos podem ser vendidos a um valor maior do que seu custo de produção.

Porém, dado que o desenvolvimento de inserção de novos bens e serviços no mercado também está intrinsecamente relacionado à criação de bem-estar para a sociedade (SCHUMPETER, 1934; KIRZNER, 1997 apud COMPANYS; McMULLEN, 2007 p. 301), o estudo do processo de descoberta, avaliação e exploração de oportunidades é crucial para estudos relacionados com o tema sustentabilidade.

Como visto, o empreendedorismo sustentável pode ser, em parte, compreendido como uma função de produção, ou seja, a quantidade máxima de produtos e serviços que podem ser produzidos dada uma determinada quantidade de fatores produtivos e uma determinada tecnologia. Seu principal objetivo seria produzir bens e serviços que atuem nas soluções dos

\footnotetext{
${ }^{4}$ A necessidade de aprofundar o entendimento do campo sobre as fontes de oportunidades no empreendedorismo já havia sido alertada por Venkataraman (1997).
} 

problemas da sociedade. Assim, o potencial de uma oportunidade para gerar valor econômico, social ou ambiental está relacionado à sua capacidade de expandir a fronteira de produção, ou seja, o quanto ela possibilita a introdução de novos bens e serviços que maximizem, de forma integrada, a solução dos problemas sociais, ambientais e econômicos da sociedade.

Segundo Companys e McMullen (2007), as principais fontes de oportunidades são: mudanças na informação disponível para a sociedade sobre seus recursos materiais; mudanças nas interpretações ou preferências por meio de inovações culturais; ou mudanças no interpretador, no próprio ambiente em que ele está inserido. Diferentes escolas de empreendedorismo estudaram essas fontes de oportunidades, dentre elas, para o estudo do empreendedorismo sustentável, destacam-se a econômica e a cognitiva cultural.

A escola econômica está focada nas dimensões objetivas do conhecimento e da informação. Atribui a existência de entrepreneurial opportunities à distribuição assimétrica de informações sobre oportunidades materiais na sociedade (ARROW, 1962 apud COMPANYS; McMULLEN, 2007). Essa escola postula que atores econômicos, em geral, são ignorantes a respeito de oportunidades (KIRZNER, 1973), limitados no acesso à informação e, portanto, na melhor forma de descobrir recursos e explorá-los (SHANE; VENKATARAMAN, 2000). Assim, na medida em que um ator econômico seja o primeiro a descobrir e explorar uma oportunidade, ele obterá uma vantagem competitiva (LIEBERMAN; MONTGOMERY, 1988). Com o tempo, todos obterão acesso à mesma informação, fonte da vantagem competitiva e, ao explorarem a mesma oportunidade, o mercado encontra um equilíbrio (KIRZNER, 1997).

As oportunidades empreendedoras surgem, primeiramente, porque diferentes pessoas possuem diferentes crenças sobre o valor relativo dos recursos disponíveis e, assim, podem transformá-las de diferentes formas em estados diferentes (KIRZNER, 1997). Nem todas as oportunidades são necessariamente óbvias para todos em um mesmo momento (HAYEK, 1945 apud SHANE; VERKATARAMAN, 2000). Por outro lado, existe a possibilidade de que uma oportunidade seja identificada simultaneamente por vários empreendedores. Isto somente será descoberto por um deles caso algum dos outros comece a explorá-la ao mesmo tempo (CASSON, 2005). Para que existam oportunidades empreendedoras, deve haver um momento em que não há consenso entre as pessoas sobre o valor de determinados recursos (ECKHARDT; SHANE, 2003).

A distribuição assimétrica de informações na sociedade pode ser entendida como uma violação aos pressupostos de um mercado perfeitamente competitivo. Essa violação é 

denominada de falha de mercado. Quando esta ou outra falha, como externalidades, bens públicos e monopólios, ocorre, os mercados não operam eficientemente (VENKATARAMAN, 1997; DEAN; McMULLEN, 2002). Muitos dos problemas ambientais existentes na atualidade são atribuídos a essas falhas de mercado (DEAN; McMULLEN, $2007^{5}$ ), e a economia ambiental é o campo de conhecimento que estuda o impacto dessas falhas sobre o meio ambiente (CROPPER; OATES, 1992). Da mesma forma, postula que a correção dessas falhas aumenta a eficiência dos mercados enquanto, simultaneamente, reduz a degradação ambiental e os efeitos da poluição (BUCHANAN; FAITH, 1981). Kirzner (1973) sugere que o processo de alocação de recursos na sociedade pode se tornar mais eficaz a partir da identificação e exploração de oportunidades por empreendedores.

Considerando essa e outras discussões sobre as fontes de oportunidades, Eckhardt e Shane (2003, p. 341) distinguem alguns importantes temas a esse respeito na literatura. O primeiro foca os choques exógenos que alteram a demanda (ex. gostos e preferências) ou a oferta (ex. tecnologia) de um mercado. As mudanças resultantes produzem oportunidades para a ação empreendedora. Em contraste, outro tema foca nas assimetrias no reconhecimento dessas mudanças pelo empreendedor, resultado de diferenças individuais como conhecimento (HAYEK, 1945) ou da perspicácia ${ }^{6}$ (KIRZNER, 1973) do empreendedor.

Em face dessas considerações, é possível concluir que oportunidades são inerentes às falhas de mercado e apresentam possibilidade de melhoria do bem-estar social. Por outro lado, a economia ambiental explica que a degradação ambiental decorre das falhas de mercado. Portanto, falhas de mercado, ambientalmente relevantes, podem proporcionar oportunidades para, simultaneamente, gerar valor econômico enquanto se reduzem problemas ambientais, o que, em última instância, promove o desenvolvimento social. Dessa forma, é possível caracterizar as oportunidades de negócios sustentáveis como sendo aquelas que proporcionam aos empreendedores a possibilidade de solucionarem falhas de mercado ambientalmente relevantes de forma a aumentar o bem-estar social e promover o desenvolvimento sustentável da sociedade.

Esse conceito é coerente com as premissas de Cohen e Winn (2007) sobre a existência de mercados natural e ambientalmente relacionados com imperfeições e a geração de entrepreneurial opportunities por meio do processo de percepção, descoberta e criação por

\footnotetext{
${ }^{5}$ Esses autores utilizam os princípios da Teoria da Ecologia Moderna "o sistema de mercado e as instituições provenientes dele evoluem no tempo de forma a resolver seus próprios problemas". Para um maior detalhamento ver Hajer, 1995.

6 Entrepreneurial alertness: habilidade para perceber, sem necessariamente estar procurando, oportunidades que até então foram negligenciadas (ver GAGLIO, 2001).
} 
empreendedores que, ao explorarem essas imperfeições, têm o potencial de criar valor financeiro. Também é coeso com os argumentos de Dean e Mcmullen (2007) quando postulam que as falhas de mercado são fonte de entrepreneurial opportunities e que os recursos naturais, sendo particularmente mais suscetíveis, apresentam-se como fontes em potencial. Ainda, a ação empreendedora, ao explorar essas falhas, leva a uma situação de maior bem-estar social, reduz impactos ambientais e melhora a sustentabilidade dos mercados.

A escola cultural cognitiva, em contraste com a escola econômica, posiciona as entrepreneurial opportunities como um fenômeno subjetivo. Subjetivo porque os autores consideram que as oportunidades são contingentes ao grau de ambiguidade e de habilidade dos atores sociais em desenvolver modelos mentais necessários para interpretá-las e defini-las como oportunidades. Essa escola sugere que oportunidades existem uma vez que elas são definidas e representadas por indivíduos e empresas (WEICK, 1979). Apresenta similaridade com a escola econômica uma vez que postula que as assimetrias de informação são as principais fontes de entrepreneurial opportunities. Entretanto diferencia-se por considerar que essa assimetria é fruto de sistema social culturalmente enraizado nos significados e crenças de uma sociedade. Os atores sociais não as descobrem e, sim, as constroem no desenvolvimento de novos sentidos e significados (SWIDLER, 1986). Os atores sociais variam em seu conhecimento cultural e na experiência anterior; portanto a pose de conhecimentos culturais distintos (RINDOVA; FOMBRUN, 1999) e a melhor utilização da informação disponível (CASSON, 2005) são a base para vantagem competitiva. Dessa forma, as oportunidades são contingentes à experiência anterior do empreendedor (EISENHARDT; SCHOONHOVEN, 1996), a suas habilidades cognitivas, à capacidade de absorção, à inteligência e ao acesso a redes sociais (SHANE, 2000).

Para Baker et al. (2005), as diferenças nos gostos e nas preferências individuais estão relacionadas e influenciadas pelo contexto nacional. Assim, o contexto e a cultura nacional podem influenciar na percepção, descoberta e exploração de oportunidades. $\mathrm{O}$ valor material dos objetos depende de como eles serão utilizados, o que, por fim, depende dos gostos e necessidades de seus usuários. Dessa forma, mudanças nas interpretações são consideradas fontes de entrepreneurial opportunities, e o empreendedor que possui melhores informações tem possibilidade de influenciar essas mudanças (COMPANYS; McMULLEN, 2007).

Essa escola está associada com o trabalho de Zahra (2008) em um estudo sobre a globalização do empreendedorismo social. O autor utiliza a Teoria Comportamental da Firma 
(CYERT; MARCH, 1963) para argumentar que qualquer proposta para conceituação de oportunidades sociais deve refletir o entendimento de indivíduos e organizações sobre a sociedade (SIMON, 1979). A natureza das causas sociais e do contexto social restringe as escolhas dos empreendedores; assim, o conceito da natureza das oportunidades para empreendedorismo social emerge do entendimento de como os empreendedores processam as informações e tomam suas decisões (ZAHRA, 2008).

Dessa forma, considerando que o contexto social restringe as escolhas dos empreendedores e assumindo que a escola econômica reflete apenas a busca por valor financeiro, esse autor propõe a utilização da Teoria Comportamental para delinear a viabilidade de uma oportunidade social. Em suma, ele sugere que o comportamento de um empreendedor social, seus processos decisórios perante causas sociais é explicado pelo grau de satisfação obtido em atender ao problema. Em outras palavras, a percepção e o descobrimento de uma oportunidade para ação empreendedora partirá de critérios não econômicos.

Zahra (2008) atribui cinco características às oportunidades no empreendedorismo social. Esses atributos demonstram a complexidade dos processos decisórios dos empreendedores sociais e auxiliam a diferenciar oportunidades de negócios das sociais. O primeiro atributo diz respeito à prevalência de necessidades humanas, à continuidade e extensão de um problema, como a fome ou a escassez de água. A teoria comportamental sugere que empreendedores, desejosos da melhoria do bem-estar, estarão mais propensos a identificar oportunidades em causas sociais mais profundas porque essas são mais evidentes para eles. O segundo é a relevância de um problema, o quanto uma causa é proeminente para a sociedade. Eles utilizam a relação entre a importância atribuída à causa em seu contexto social com suas experiências, valores, talentos, habilidades e recursos para tomar decisões. O terceiro é a urgência (social), a qual, em geral, ocorre como resposta a eventos imprevistos, como furacões, guerras, enchentes ou incêndios, que necessitam de uma ação imediata. $\mathrm{O}$ quarto, a acessibilidade, diz respeito ao nível percebido de dificuldade em atendimento a uma causa social por meio de mecanismos humanitários usuais e, por fim, o quinto é o caráter radical do problema, que está relacionado a quanto uma mudança social é necessária para melhoria do bem-estar da sociedade.

Oportunidades de negócios, especificamente para a criação de valor econômico, dificilmente atenderiam a essas características. Por exemplo, a prevalência se contrapõe à proposta de atuação dos empreendedores em nichos (PORTER, 1980). De forma similar, a 
urgência não define oportunidades economicamente viáveis; de forma contrária, deseja-se que a oportunidade desapareça rapidamente. Por fim, esses atributos conferem as oportunidades de viabilidade do ponto de vista social, mas não necessariamente pelo lado econômico. É o valor social que determina, em última instância, o comportamento do empreendedor.

Ainda que esses atributos se combinem para delinear oportunidades sociais, eles são especialmente úteis para complementar a definição de oportunidades de negócios sustentáveis. Segundo Zahra (2008), empreendedores têm diversas opções de capitalizar as oportunidades sociais com os atributos apresentados. Da mesma forma, as oportunidades para negócios sustentáveis refletem a criação de valor social por meio da geração de valor econômico. Assim, é possível atribuir essas características também às oportunidades de negócios sustentáveis. Mais especificamente, elas apresentam uma forma de diferenciar entrepreneurial opportunities, que visam apenas à geração de valor econômico, ainda que de forma socialmente responsável?

\footnotetext{
${ }^{7}$ É importante distinguir empresas direcionadas pelo senso de responsabilidade social, ou seja, agir de forma responsável enquanto perseguem interesses privados, daquelas direcionadas pelo propósito de contribuir para o desenvolvimento ecológico e social do sistema em que vivem (PARRISH, 2008).
} 


\section{O RECONHECIMENTO DE OPORTUNIDADES}

Saravasthy et al. (2003), a partir dos trabalhos de Hayek (1945), Knight (1921) e Buchanan e Vanberg (1991), delinearam três visões conceituais distintas, porém não mutuamente exclusivas, do processo de reconhecimento de oportunidades no empreendedorismo. A primeira, allocative view, atada ao processo de reconhecimento ou percepção da oportunidade, direciona a existência de uma oportunidade para quando há potencial para redistribuição de recursos, pelo lado da oferta ou da demanda, movendo-se para alocações Pareto $^{8}$. A segunda, distributive view, relacionada ao processo de descoberta, sugere que as oportunidades são decorrentes das assimetrias de informações sobre o valor dos recursos e do resultado de suas potenciais combinações. Por fim, a terceira, creative view, vinculada ao processo de criação, sugere que os empreendedores buscam maximizar as funções de utilidades de diversos stakeholders, e os empreendedores estabelecem um mercado novo.

Shane e Venkataraman (2000) apresentam dois fatores importantes que possibilitam o reconhecimento de uma oportunidade: a posse de informação anterior necessária e propriedades cognitivas para avaliá-la. Para Roberts (1991), informações anteriores, adquiridas a partir de experiências, educação ou redes, influenciam a habilidade cognitiva do empreendedor em compreender, extrapolar, interpretar e aplicá-las no reconhecimento de uma oportunidade. Os empreendedores desenvolvem competências durante sua vida que os habilitam a criar novos negócios. Para reconhecer uma oportunidade, o empreendedor necessita ter informações prévias que, combinadas com novas informações, criam uma conjectura empreendedora que viabiliza o início do processo (KAISH; GILAD, 1991). Para Casson (2005), o empreendedor necessita obter um monopólio de determinadas informações que indicam que há potencial de lucro em uma oportunidade aparente.

Shane (2000) postula que há três dimensões sobre conhecimento anterior que são importantes no processo de descoberta de oportunidades: mercados, formas de atendimento ao mercado e demandas do consumidor. Conforme Shane (2000), o empreendedor deve ter conhecimento não apenas sobre a existência de uma necessidade mas também sobre os meios de satisfazê-la. Portanto, o problema social ou ambiental pode existir, porém, se o empreendedor não tiver os meios para solucioná-lo, este não representará uma oportunidade

\footnotetext{
${ }^{8}$ Para uma revisão mais detalhada de eficiência de Pareto e sua relação com bem estar social, ver Varian (2001).
} 

de negócio sustentável. Portanto, o conhecimento anterior dos empreendedores influenciará a descoberta de oportunidades de novos negócios sustentáveis.

Para Mair e Marti (2006), o empreendedor social está conectado ao ambiente (comunidade e sociedade) onde ele vive. Weerawardena e Mort (2006) propuseram que empreendedores sociais são não apenas responsáveis, mas também condicionados por sua dinâmica ambiental. Isto implica que não apenas eles reconhecem essas oportunidades no ambiente em que habitam, como também o meio será um fator limitante com relação a novas ideias. Assim, os indivíduos que estão em contato com um ambiente específico apresentam maior conhecimento e melhor preparo para perceber as necessidades aí existentes. Entretanto também serão mais limitados por ele na busca por soluções e inovações para problemas e causas sociais e ambientais, o que impacta a descoberta de oportunidades de novos negócios sustentáveis.

A posse de informações anteriores, conhecimento anterior das necessidades e os meios para satisfazê-las são requeridos para o reconhecimento de uma oportunidade de novos negócios sustentáveis. Entretanto esses fatores devem estar cognitivamente ligados para que uma oportunidade se realize (SHRADER; HILLS, 2006). Kirzner (1973) foi o primeiro a visualizar que empreendedores possuem uma qualidade distinta que lhes possibilita enxergar essas oportunidades; a essa característica, ele denominou perspicácia, a habilidade para perceber, sem necessariamente estar procurando oportunidades que até então foram negligenciadas. $\mathrm{O}$ empreendedor deve ser capaz de determinar novas relações entre meios e fins, identificando, assim, o potencial comercial do que está concebendo (SHANE; VENKATARAMAN, 2000).

Em suma, o reconhecimento de oportunidades de negócios sustentáveis apresenta uma série de requisitos necessários. O empreendedor precisa, primeiro, identificar uma necessidade na forma de uma causa ou problema, social ou ambiental. Essa condição, entretanto, não é suficiente, pois os empreendedores devem também identificar os meios de atendê-la, ou seja, criar valor social e ambiental, a partir da geração de valor econômico. Finalmente, ele precisa, cognitivamente, unir esses dois conhecimentos em um objeto coerente que pode então ser chamado de oportunidade de negócios sustentáveis. Assim, oportunidades para negócios sustentáveis são reconhecidas quando o empreendedor cognitivamente relaciona seu conhecimento a uma causa social ou ambiental aos meios de satisfazê-la. 
Outra importante variável, que pode ter um significativo impacto no reconhecimento de oportunidades de negócios sustentáveis, são as redes sociais. A experiência profissional e de vida do empreendedor, assim como sua rede social de relacionamentos podem contribuir para que ele tenha a percepção de que uma ideia possa se constituir em uma oportunidade potencial (SINGH; HYBELS; HILLS 2000; ALSOS; KAIKKONEN, 2004). De Koning (1999 apud PHILLIPS; TRACEY, 2007), Hills, Lumpkin e Singh (1997) e Birley (1985) já haviam postulado sobre a importância das redes sociais na identificação de oportunidades no empreendedorismo. Trata-se de um aspecto basicamente intuitivo e não linear relacionado à criatividade (LUMPKIN; HILLS; SHRADER., 2001 p. 74), com base no fato de existir uma heterogeneidade da sensibilidade de cada indivíduo na percepção de oportunidades voltadas para a criação de um novo valor (ARDICHVILI; CARDOZO; RAY, 2003). Ardichvili, Cardozo e Ray (2003) propõem que a perspicácia do empreendedor pode ser melhorada por meio de suas redes de contatos.

Na pesquisa sobre empreendedorismo social, vários autores também enfatizaram a importância das redes de contato, não apenas como fonte de oportunidades sociais, mas também porque proporcionam acesso a informação, recursos e suporte (MAIR; MARTÍ 2006). No empreendedorismo sustentável, Schlange (2007), em um estudo empírico sobre a motivação dos empreendedores sustentáveis com fundadores de pequenas empresas suíças que apresentavam modelos de negócios sustentáveis, identificou que os fatores impacto, legitimidade e fílosofia são determinantes no desenvolvimento de um novo negócio. $\mathrm{O}$ autor também identificou que a rede de contatos influenciava no direcionamento de seus negócios. Dixon e Clifford (2007), em um estudo de caso sobre sistemas de negócios sustentáveis com uma pequena empresa do Reino Unido, demonstraram que a empresa teve condições de progredir por causa do modelo de rede estabelecido com organizações grandes e empresas convencionais, com a comunidade e com o governo. Em suma, as redes de contato têm potencial para incrementar a perspicácia dos empreendedores em oportunidades de negócios sustentáveis.

A pesquisa em empreendedorismo também vem sendo conduzida de forma a demonstrar fatores e motivações que possibilitam ao empreendedor identificar oportunidades para criação de valor e desenvolvimento econômico (SHANE, 2000). A oportunidade relacionada com a esfera social considera as motivações individuais para eleição de uma causa social (ZAHRA, 2008), enquanto a ambiental considera fatores que motivam inovações de produtos e processos de soluções ambientais (SCHALTEGGER, 2002). 
Schlange (2007) identificou, em seu estudo de caso, que os empreendedores de negócios sustentáveis são motivados pelo desejo de potencializar o desenvolvimento regional e, fazendo isso, buscam incorporar valores na economia regional e no sistema social. Os empreendedores direcionados à sustentabilidade também se destacaram pela habilidade de, simultaneamente, traçar e alcançar objetivos nas esferas sociais, ambientais e econômicas. Esse estudo sugere que não são apenas os valores e motivações dos empreendedores sustentáveis que os diferem dos outros mas também suas capacidades.

Dixon e Clifford (2007) também identificam que o perfil empreendedor do dono foi fator determinante do sucesso da empresa; além disso, as motivações sociais e ambientais do empreendedor proporcionaram o crescimento do negócio sem perder o foco no objetivo social e ambiental. Cohen, Smith e Mitchell (2006) sugerem que, no empreendedorismo sustentável, a criação de valor do negócio será distinta, de acordo com qual esfera de valor os motivos do empreendedor estarão relacionados; empreendedores sustentáveis seriam aqueles motivados pelas três esferas. Dessa forma, os empreendedores irão avaliar as oportunidades de negócios sustentáveis baseados no valor social, ambiental e econômico que poderá ser criado na exploração dessa oportunidade. 
O presente ensaio teórico buscou contribuir para a compreensão do processo de criação das organizações que apresentem motivações sociais e ambientais além das econômicas. Procurou entender o processo empreendedor como forma de estímulo do desenvolvimento econômico e solução de problemas ambientais e sociais, por meio da análise das fontes e do processo de descoberta de oportunidades de negócios sustentáveis.

Como visto, o empreendedorismo sustentável pode ser, em parte, compreendido como uma função de produção. Seu principal objetivo seria produzir bens e serviços que atuem nas soluções dos problemas da sociedade. Assim, o potencial de uma oportunidade para gerar valor econômico, social ou ambiental está relacionado à sua capacidade de expandir a fronteira de produção, ou seja, o quanto ela possibilita a introdução de novos bens e serviços que maximizem, de forma integrada, a solução dos problemas sociais, ambientais e econômicos da sociedade.

Também foi possível observar que oportunidades são inerentes às falhas de mercado e apresentam possibilidade de melhoria do bem-estar social. Por outro lado, a economia ambiental postula que a degradação ambiental decorre das falhas de mercado. Portanto, falhas de mercado, ambientalmente relevantes, podem proporcionar oportunidades para, simultaneamente, gerar valor econômico para a redução dos problemas ambientais, o que, em última instância, promove o desenvolvimento social. Dessa forma, é possível caracterizar as oportunidades de negócios sustentáveis como sendo aquelas que proporcionam aos empreendedores a possibilidade de solucionarem falhas de mercado ambientalmente relevantes de forma a aumentar o bem-estar social e promover o desenvolvimento sustentável da sociedade.

Com relação aos fatores que influenciam na identificação dessas oportunidades pelos empreendedores na criação de novos empreendimentos, o reconhecimento de oportunidades de negócios sustentáveis apresenta uma série de requisitos necessários. O empreendedor precisa, primeiro, identificar uma necessidade na forma de uma causa ou problema, social ou ambiental. Essa condição, entretanto, não é suficiente, pois os empreendedores devem também identificar os meios de atendê-la, ou seja, criar valor social e ambiental, a partir da geração de valor econômico. Finalmente, ele precisa, cognitivamente, unir esses dois conhecimentos em um objeto coerente que pode então ser chamado de oportunidade de negócios sustentáveis. Assim, oportunidades para negócios sustentáveis são reconhecidas quando o empreendedor cognitivamente relaciona seu conhecimento anterior de uma causa 
social ou ambiental aos meios de satisfazê-la. Verifica-se ainda que as redes de contato também tenham potencial para incrementar a perspicácia dos empreendedores a oportunidades de negócios sustentáveis, e os empreendedores avaliarão as oportunidades de negócios sustentáveis baseados no valor social, ambiental e econômico que poderá ser criado na exploração dessa oportunidade.

Por fim, espera-se que este ensaio teórico possa contribuir para a ampliação do foco dos estudos sobre empreendedorismo, pois poucos trabalhos enfocando o tema empreendedorismo sustentável foram realizados no país. A teoria voltada para o setor que envolve as organizações com outros fins além do econômico está em processo de formação, portanto é necessário desenvolver mais estudos voltados para o tema. Da mesma forma, possa contribuir e auxiliar os futuros estudos sobre novos negócios empreendedores, principalmente durante as etapas da identificação de oportunidades de negócios que solucionem problemas sociais e ambientais, entendendo como essas soluções se constituem oportunidades de negócios sustentáveis. 


\section{REFERÊNCIAS}

AHMED, A.; MCQUAID, R. W. Entrepreneurship, Management, and Sustainable Development. World Review of Entrepreneurship, Management and Sustainable Development, v. 1, n. 1, p. 6-30, 2005.

ALSOS, G. A.; KAIKKONEN, V. Opportunities and prior knowledge: a study of experienced entrepreneurs. Frontiers of Entrepreneurship Research. Wellesley: Babson College, 2004. Disponível em: <http://www.babson.edu/entrep/fer/FER_2004/webcontent/Section\%20XIII/P1/XIII-P1.html>. Acesso em: 12 nov. 2008.

ALVAREZ, S; BARNEY, B. Discovery and creation: Alternative Theories of Entrepreneurial Action. Strategic Entrepreneurship Journal, v. 1, pp. 11-26, 2007

ALVORD, S. H. BROWN, L. D.; LETTS, C. W. Social entrepreneurship and societal transformation. Journal of Applied Behavioral Science, v. 40, n. 3, p. 260-282, 2004.

ANDERSON, A. R. Cultivating the Garden of Eden: Environmental Entrepreneuring. Journal of Organizational Change Management, v. 11, n. 2, p. 135-144, 1998.

ANDERSON, T. A.; LEAL, R. Free market versus political environmentalism. Harvard Journal of Law and Public Policy, v. 15, n. 2, p. 297-310, 1992.

ARDICHVILIA, A.; CARDOZO, R. RAY, S. A Theory of Entrepreneurial opportunitty, identification and development. Journal of Bussiness Venturing, v. 18, n. 1, p. 105-123. 2003.

AUSTIN, J.; STEVENSON, H,; WEI-SKILLERN J. Social and Commercial Entrepreneurship: Same, Different, or Both? Entrepreneurship Theory and Practice, v. 30, n. 1, p. 1-22, 2006.

BAKER, et al. A framework for comparing entrepreneurship processes across nations. Journal of International Business Studies v. 36, n. 5, p. 492-504, 2005.

BIRLEY, S. The Role of Networks in. the Entrepreneurial Process. Journal of Business Venturing, v. 1, n. 1, p. 107-117, 1985.

BHIDÉ, A. V. The Origin and Evolution of New Business. New York: Oxford, 2000.

BOSCHEE, J. Social entrepreneurship: Across the Board 32. 1995 Disponível: <http://www.prescott.edu/ faculty staff/faculty/scorey/documents/boschee_1995.pdf>. Acesso: jan. 2009.

BRYANT, T. A.; BRYANT, J. E. Wetlands and Entrepreneurs: Mapping the Fuzzy Zone Between Ecosystem Preservation and Entrepreneurial Opportunity. Journal of Organizational Change Management, v. 11, n. 2, p. 112-134, 1998. 
BUCHANAN, J. M.; FAITH, R. L. Entrepreneurship and the internationalization of externalities. Journal of law and Economics, v. 24, n. 1, p. 95-111, 1981.

BUCHANAN, J. M.; VANBERG, V. J. The market as a creative process. Economics and Philosophy, v. 7, n. 2, p. 167-186, 1991.

BYGRAVE, W. D. The entrepreneurial process. In: BYGRAVE, William D. (Ed.) The portable MBA in entrepreneurship. New York: John Wiley; Sons, Inc., 1997. p. 1-26.

CASSON, M. Opportunity Nexus: A Review of Scott Shane: A General Theory of Individual Entrepreneurship. Small Business Economics, v. 24, n. 5, p. 423-430, 2005.

CERVO, A.; BERVIAN, P. Metodologia científica. 5. ed. São Paulo: Prentice Hall, 2002.

CHELL, E. Social enterprise and entrepreneurship: towards a convergent theory of the entrepreneurial process. International Small Business Journal, v. 25, n. 1, p. 5-26, 2007.

COHEN, B.; SMITH, B.; MITCHELL, R. Toward a Sustainable Conceptualization of Dependent Variables in Entrepreneurship Research. Business Strategy and the Environment, v. 17, n.2, p. 107-119, 2006.

COHEN, B.; WINN, M. I. Market Imperfections, Opportunity and Sustainable Entrepreneurship. Journal of Business Venturing, v. 22, n. 1, p. 29-49, 2007.

COMISSÃO MUNDIAL SOBRE MEIO AMBIENTE E DESENVOLVIMENTO. Nosso Futuro Comum. 2. Ed. Rio de Janeiro: Editora da Fundação Getúlio Vargas, 1991. 430p.

COMPANYS, Y.; McMULLEN, J. S. Strategic Entrepreneurs at Work: The Nature, Discovery, and Exploitation of Entrepreneurial Opportunities. Small Business Economics, v. 28, n. 4, p. 273-283, 2007.

CROPPER, M. L.; OATES, W. E. Environmental economics: a survey. Journal of Economic Literature, v. 30, n. 1, p. 675- 740, jun. 1992.

CYERT, R. M; MARCH J. G. A Behavioral Theory of the Firm. Prentice-Hall: Englewood Cliffs, NJ, 1963.

DEAN, T. J.; MCMULLEN, J. S. Toward a Theory of Sustainable Entrepreneurship: Reducing Environmental Degredation Through Entrepre neurial Action. Journal of Business Venturing, v. 22, n. 1, p. 50-76, 2007.

DEES, J.G. The Meaning of "Social Entrepreneurship". Ewing Marion Kauffman Foundation and Standford University. 1998. Disponível em: <http://www.caseatduke. org/documents/dees_sede f.pdf>. Acesso em: jan. 2009.

DEES, J. G. The Meaning of "Social Entrepreneurship". Ewing Marion Kauffman Foundation and Standford University. 1998. Disponível: http://www.caseatduke. org/documents/dees_sede f.pdf. Acesso: jan. 2009 
DELGADO, N.; CRUZ, L.; PEDROZO, E.; SILVA, T. Empreendedorismo orientado a sustentabilidade: as inovações do caso Volkmann Cadernos EBAPE. BR, v. 6, n. 3. Set. 2008.

DIXON, S. E. A.; CLIFFORD, A. Ecopreneurship - A New Approach to Managing the Triple Bottom Line. Journal of Organizational Change Management, v. 20, n. 3, p. 326-345, 2007.

ECKHARDT, J. T.; SHANE, S. A. Opportunities and entrepreneurship. Journal of Management, v. 29, n. 3, p. 333-349, 2003.

EISENHARDT, K. M.; SCHOONHOVEN, C. B. Resource-Based View of Strategic Alliance Formation: Strategic and Social Effects in Entrepreneurial Firms, Organization Science, v. 7, n. 2, p. 136-150, 1996.

ELKINGTON, J.; HARTIGAN, P. Power of Unreasonable People: How Social Entrepreneurs Create Markets that Change the World. Cambridge, MA: Harvard Business School Press Books, 2008.

FREIMANN, J.; MARXEN, S.; SCHICK, H. Sustainability Issues for Start-Up Entrepreneurs Greener Management International, Issue 38, p. 59, Summer 2002. 12p.

GAGLIO, C. M.; KATZ, J. A. The Psychological Basis of Opportunity Identification: Entrepreneurial Alertness. Small Business Economics, v. 16, n. 2, p. 95-111, 2001.

GARTNER, W. B. A framework for describing the phenomenon of new venture creation. Academy of Management Review, v. 10, n. 4, p. 696-706, 1985.

GERLACH, A. Sustainability entrepreneurship in the context of emissions trading. In: ANTES, R., HANSJÜRGENS, B.; LETMATHE, P. Emissions Trading and Business. Heildelberg: Physica-Verlag, 2006. p. 73-91.

GIBB, A. A. Entrepreneurship and Small Business Management: Can We Afford to Neglect Them in the Twenty-First Century Business School? British Journal of Management, v. 7, n. 4, p. 309-322, 1996.

GLADWIN, T. N.; KENNELLY, J. J; KRAUSE, T. S. Shifting Paradigms for Sustainable Development: Implications for Management Theory and Research. Academy of Management Review, v. 20, n. 4, p. 874-907, 1995.

HAJER, M. The Politics of Environmental Discourse: Ecological Modernization and the Policy Process. Oxford: Oxford University Press, 1995. 332p.

HAYEK, F. A. The use of knowledge in society. The American Economic Review, v. 35, n. 4, p. 519-520, 1945.

HILLS, G. E.; LUMPKIN, G. T.; SINGH, R. P. Opportunity recognition: perceptions and behaviors of entrepreneurs. Frontiers of entrepreneurship research. Babson College, 1997. Disponível em: <http://www.babson.edu/entrep/fer/papers97/hills/hill1.htm>. Acesso em: jan. 2009. 
HOMANS, G. C. Social Behavior: Its Elementary Forms. New York: Harcourt Brace Jovanovich, Inc. 1964.

ISAAK, R. The Making of the Ecopreneur. Greener Management International, v. 38,p. 8191, 2002.

JACOBS, M. Sustainable development, capital substitution and economic humility: a response to Beckerman. Environmental Values, v. 4, n. 1, p. 57-68, 1995.

KAISH, S; GILAD, B. Characteristics of Opportunities Search of Entrepreneurs: Sources, Interests, General Alertness. Journal of Business Venturing, v. 6, n. 1, p. 45-61, 1991.

KATZ, D.; GARTNER, W, B. Properties of Emerging Organizations. Academy of Management Review, v. 13, n. 3, p. 429-441, 1988.

KIRZNER, I. Competition and Entrepreneurship. Chicago, IL: Chicago Press, 1973.

KIRZNER, L. M. Entrepreneurial Discovery and the competitive market process: an Austrian approach. Journal of Economic Literature, v. 35, n. 1, 60-85, 1997.

KNIGHT, F. H. Risk, Uncertainty and Profit. Boston: Houghton Mifflin Company, 1921.

LUMLEY, S.; ARMSTRONG, P. Some of the nineteenth century origins of the sustainability concept. Environment, Development and Sustainability, v. 6, n. 1, p. 367-378, 2004.

LUMPKIN, T. G.; HILLS, G. E.; SHRADER, R. C. Opportunity Recognition. In: WELSCH, H. P. (Ed.). Entrepreneurship: The Way Ahead. New York: Routledge, 2004. p. 73-90.

LIEBERMAN, M. B.; MONTGOMERY, D. B. First Movers Advantages. Strategic Management Journal, v. 9, n. 1, p. 41-58, 1988.

MAIR, J.; MARTI, I. Social entrepreneurship research: a source of explanation, prediction, and delight. Journal of World Business, v. 41, n. 1, p. 36-44, 2006.

MCMULLEN, J. S; SHEPHERD, D. A. Entrepreneurial Action and the Role of Uncertainty in the Theory of the Entrepreneur. Academy of Management Review, v. 31, n. 1, p. 132-152, 2006.

MORGAN, G. Imagens da Organização. São Paulo: Atlas, 1996.

PARRISH, B. D. Sustainability-Driven Entrepreneurship: A Literature Review. Leeds, UK: University of Leeds, 2008.

PASTAKIA, A. Assessing Ecopreneurship in the Context of a Developing Country. Greener Management International, v. 38, p. 93-108, 2002.

PERRINI, F.; VURRO, C. Social Entrepreneurship: Innovation and Social Change Across Theory and Practice. In: MAIR, J.; ROBINSON, J.; HOCKERTS, K. (Ed.). Social Entrepreneurship. New York: Palgrave MacMillan, 2006. P. 57-85. 
PHILLIPS, N.; TRACEY, P. Opportunity Recognition, Entrepreneurial Capabilities and Bricolage: Connecting Institutional Theory and Entrepreneurship in Strategic Organization. Strategic Organization, v.5, n. 3, p. 313-320, 2007.

PHILLIS, J.; DENEND, L. Social Entrepreneurs: Correcting Market Failures In: Project Impact, One World Health, Benetech. Stanford Graduate School of Business, 2005.

PORTER, M. Competitive strategy: techniques for analizing industries and competitors. New York: The Free Press, 1980.

RINDOVA, V. P; FOMBRUN, C. J. Constructing Competitive Advantage: The Role of FirmConstituent Interactions. Strategic Management Journal, v. 20, n. 8, p. 691-710, 1999.

ROBERTS, E. (1991) Entrepreneurs in High Technology: Lessons from MIT and Beyond. New York: Oxford University Press. Disponível em: <http://books.google.com>. Acesso em: 11 nov. 2008.

SAGAWA, S.; SEGAL, E. Common Interest, Common Good: Creating Value Through Business and Social Sector Partnerships. California Management Review, v. 42, n. 2, p. 105-122, 2000.

SARASVATHY, S. D.; DEW, N.; VELAMURI, R.; VENKATARAMAN, S. Three views of entrepreneurial opportunity. In: ACS, Z. J.; AUDRETSCH, D. B. (Ed.). Handbook of Entrepreneurship Research: An Interdisciplinary Survey and Introduction. Kluwer: Boston, 2003. p. 141-160.

SCHALTEGGER, S. A Framework for Ecopreneurship. Greener Management International, v. 38, p. 45-58, 2002.

SCHAPER M. The Essence of Ecopreneurship. Greener Management International, v. 38, p. 26-30, 2002.

SCHLANGE, L. E. Stakeholder Perception in Sustainable Entrepreneurship: The Role of Managerial and Organizational Cognition. First World Symposium on Sustainable Entrepreneurship as part of the Corporate Responsibility Research Conference. University of Leeds, Leeds, UK. 15-17 July 2007.

SCHUMPETER, J. A. A teoria do desenvolvimento econômico. São Paulo: Abril Cultural, 1982. $169 \mathrm{p}$.

SEELOS, C.; MAIR, J. Entrepreneurs in service of the poor-Models for business contributions to sustainable development, Business Horizons, v. 48, n. 3, p. 241-246, 2005.

SEVERINO, A. J. Metodologia do trabalho científico. 21. ed. São Paulo: Cortez, 2000.

SHANE, S. Explaining Variation in Rates of Entrepreneurship in the United States: 18991988. Journal of Management, v. 22, n. 5, p. 747-781, 1996. 
SHANE, S. Prior knowledge and the discovery of entrepreneurial opportunities.

Organization Science, v. 11, n. 4, p. 448-469, 2000.

SHANE, S.; VENKATARAMAN, S. The promise of entrepreneurship as a fi eld of research. Academy of Management Review, v. 25, n. 1, p. 217-226, 2000.

SHRADER, R. C; HILLS, G. E. Opportunitty Recognition: Perceptions of Highly Succesful Entrepreneurs. Journal of Small Business Strategy, v. 14, n. 2, p. 92-108, 2006.

SIMON, H. A. Rational decision making in business organizations. American Economic Review, v. 69, n. 4, p. 493-513, 1979.

SINGH, R. P.; HYBELS, R. C.; HILLS, G. E. (2000). Examining the role of social network size and structural holes to entrepreneurial opportunity recognition. New England Journal of Entrepreneurship, v. 3, n. 1, p. 59-67, 2000.

SWIDLER, A. Culture in Action: Symbols and Strategies. American Sociological Review, v. 51, n. 2, p. 273-286, 1986.

TILLEY, F.; PARRISH, B. D. From Poles to Wholes: Facilitating an Integrated Approach to Sustainable Entrepreneurship. World Review of Entrepreneurship, Management and Sustainable Development, v. 2, n. 4, p. 281-294, 2006.

TILLEY, F; YOUNG. W. Sustainability Entrepreneurs: Could They Be the True Wealth Generators of the Future? Greener Management International, v. 55, p. 79-92, 2009.

VARIAN, H. Microeconomia: Princípios Básicos - Uma abordagem Moderna. Rio de Janeiro: Campus, 2001.

VENKATARAMAN, S. The distinctive domain of entrepreneurship research. In: KATZ, J.; BROCKHAUS, R. Advances in Entrepreneurship, Firm Emergence and Growth. Greenwich, CT: JAI Press, 1997. V. 3, p. 119-138.

WADDOCK, S. A. Building successful partnerships, Sloan Management Review, v. 29, n. 4, p. 17-23, 1988 .

WALLEY, E. E.; TAYLOR, D. W. Opportunists, Champions, Macericks...? Greener Management International, v. 38, p. 31-43, 2002.

WEERAWARDENA, J.; MORT, G. S. Investigating social entrepreneurship: a multidimensional model. Journal of World Business, v. 41, n. 1, p. 21-35, 2006.

WEICK, K. E. A Psicologia Social da Organização. São Paulo: Edgard Blucher, 1979.

ZAHRA, S. et al. Globalization of Social Entrepreneurship Opportunities Strategic Entrepreneurship Journal, v. 2, n. 2, p. 117-131, 2008. 